\title{
Natural Rubber/Fluoro Elastomer Blends: Effect of Third Component on Cure Characteristics, Morphology, Mechanical Properties, and Automotive Fuel Swelling
}

\author{
Manisara Phiriyawirut ${ }^{*}$, Thalatchanan Limwongwatthananan, Surawut Kaemram, \\ Sirithada Wiengkaew \\ Department of Tool and Materials Engineering, Faculty of Engineering, King Mongkut's University of \\ Technology Thonburi, Bangkok, Thailand \\ Email: *manisara.pee@kmutt.ac.th
}

Received July 11, 2013; revised August 22, 2013; accepted September 5, 2013

Copyright (C) 2013 Manisara Phiriyawirut et al. This is an open access article distributed under the Creative Commons Attribution License, which permits unrestricted use, distribution, and reproduction in any medium, provided the original work is properly cited.

\begin{abstract}
The natural rubber (NR) was mixed with fluoro elastomer (FKM), due to the difference of polarity in NR and FKM made this blend incompatible so the third component was used. NR/FKM blended with the blend ratio of 70/30 was prepared by using a two-roll mill and vulcanization in a compression mold at $180^{\circ} \mathrm{C}$ using peroxide as a curative agent. Epoxidized natural rubber (ENR) or polyisoprene-graft-maleic acid monomethyl ester (PI-ME) was used as a third component. The curing characteristics, morphology, mechanical properties, and automotive fuel swelling were investigated. The results indicated that the scorch time and cure time of the blend rubbers were longer as adding ENR or PI-ME. Both mechanical properties and automotive fuel resistance of the blend rubbers were found to increase with adding ENR in rubber blend. Conversely for adding PI-ME, automotive fuel resistance of the blend rubbers was found to decrease progressively with increasing PI-ME content.
\end{abstract}

Keywords: Natural Rubber; Fluoro Elastomer; Epoxidized Natural Rubber; Blend

\section{Introduction}

Natural rubber (NR) from Hevea brasiliensis is known to have highly unsaturated backbone, and it also shows low oil and organic solvent resistance due to nonpolarity [1]. Owing to the presence of the polarity of the fluorine atoms in fluoro elastomer (FKM), NR/FKM blends should be resistant to ozone, oil, heat, and nonpolar chemicals. As the matter of fat, based on chemical structure, the NR/ FKM blend becomes incompatible due to the difference in polarity. The resulting blend exhibits poor mechanical properties due to the poor adhesion between the phases [2].

There are a lot publications that have discussed rubber blends based on the addition of a third homopolymer or graft or block copolymer that binds with the two phases and the introduction of bonds between the homopolymer phases [3-8]. According to Karnika de Silva and Lewwan [3] the addition of graft copolymer of NR reduced phase sizes attained in NR/NBR blends over a wide range of

\footnotetext{
*Corresponding author.
}

acrylonitrile content of NBR. K. Prakashan and coworker [4] studied compatibility problems in polypropylene (PP)/poly(dimethylsiloxane) (PDMS) elastomer blend. Maleic anhydride grafted polypropylene (PP-g-MAH) was reported to act a compatibilizer for these blends.

Epoxidized natural rubber (ENR) contains polyisoprene as main chain and epoxidize group as side group which should be reacted to NR and FKM molecules, respectively (Figure 1). Then, ENR was interested to be used as a third component for NR/FKM blend. Not only ENR but also polyisoprene-graft-maleic acid monomethyl ester (PI-ME) was interested to be used as a third component for these blend. PI-ME also contains polyisoprene as main chain and maleic acid monomethyl ester as a grafting group. The grafting group of PI-ME contains carbonyl group which should react to the FKM molecule. According to M. Abdul Kader and A. K. Bhowmick [8] reported that blend of acrylate rubber and FKM was miscibility due to interaction between $\mathrm{C}=\mathrm{O}$ group of acrylate rubber and $-\mathrm{CF}_{3}$ group of $\mathrm{FKM}$ in the blend.

In this study, the cure characteristics, morphology, 


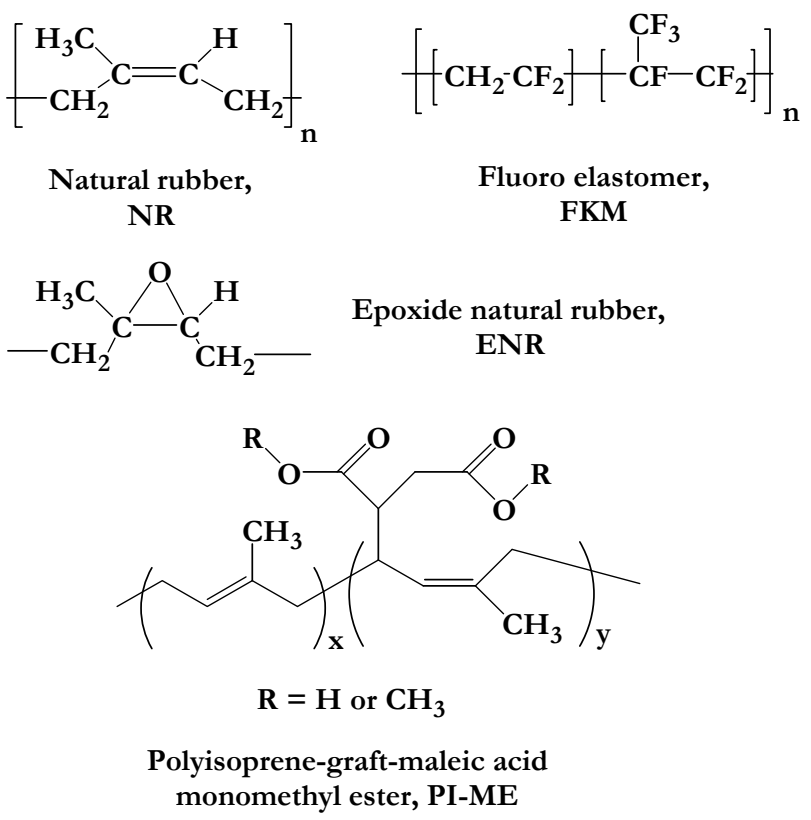

Figure 1. Chemical structure of investigated polymers.

mechanical properties, as well as automotive fuel resistances of 70/30 NR/FKM blends with and without a third component, ENR or PI-ME, were investigated. The selected automotive fuels were B5-biodiesel, diesel, gasoline and gasohol.

\section{Experimental}

\subsection{Materials}

Fluoro elastomer (FKM, Viton GF-S600) and natural vegetable wax (VPA No. 2) was supplied from Dupont Dow Elastomer Co., Ltd., USA. The natural rubber (NR) was STR 5L. Epoxidized natural rubber (ENR) was 25 mol\% of epoxide groups. Polyisoprene-graft-maleic acid monomethyl ester (PI-ME) with MW $=25,000$ was supplied from Aldrich. Organic peroxide, 2,5-dimethyl-2,4bis (t-butyl peroxy) hexane $45 \%$ active ingredient (Luperox $^{\circledR}$ 101-XL 45) was supplied from Atofina, Singapore. A coagent, triallyl isocyanurate (SR533) was provided from Sartomer, USA. Other chemicals were procured from indigenous sources and were used as such. The selected automotive fuels in this experiment were gasoline, gasohol, diesel and B5-biodiesel which were supplied from a petroleum station of PTT Public Co., Ltd., Thailand. The gasohol is a $10 \%$ ethanol blend with conventional gasoline and B5-biodiesel is a 5\% biodiesel blend with conventional diesel.

\subsection{Mixing and Vulcanization Procedure}

The compound ingredients as shown in Table $\mathbf{1}$ were mixed on a two-roll mill at room temperature. The NR was first masticated to soften it. Subsequently, given
Table 1. Compound formulation used in the preparation of the NR/FKM blends.

\begin{tabular}{|c|c|c|c|c|c|}
\hline \multirow{2}{*}{ Ingredients } & \multicolumn{5}{|c|}{ Content (phr) } \\
\hline & 1 & 2 & 3 & 4 & 5 \\
\hline NR (STR 5L) & 70 & 70 & 70 & 70 & 70 \\
\hline FKM & 30 & 30 & 30 & 30 & 30 \\
\hline ENR or PI-ME & 0 & 2.5 & 5 & 7.5 & 10 \\
\hline Carbon black (N 660) & 10 & 10 & 10 & 10 & 10 \\
\hline $6 \mathrm{PPD}^{\mathrm{a}}$ & 2 & 2 & 2 & 2 & 2 \\
\hline $\mathrm{TMQ}^{\mathrm{b}}$ & 2 & 2 & 2 & 2 & 2 \\
\hline Peroxide $^{c}$ & 3 & 3 & 3 & 3 & 3 \\
\hline SR533 & 3 & 3 & 3 & 3 & 3 \\
\hline VPA No. 2 & 0.5 & 0.5 & 0.5 & 0.5 & 0.5 \\
\hline
\end{tabular}

${ }^{\text {a }} N$-(1,3-dimethylbutyl)- $N$-phenyl-p-phenylenediamine; ${ }^{\mathrm{b}}$ Polymerized 2,2,4trimethyl-1,2-dihydroquinoline; ' 2,5 -dimethyl-2,4-bis(t-butyl peroxy) hexane $45 \%$ active ingredient.

amounts of all chemicals except Luperox ${ }^{\circledR}$ 101-XL 45 and SR533 were added to the masticated rubber. The mixture was then blended with FKM and further mixed. Lastly SR533 and Luperox ${ }^{\circledR}$ 101-XL 45 were added. To vulcanize the blends, they were compression molded using a hydraulic hot press at $180^{\circ} \mathrm{C}$ [2], under a pressure of $15 \mathrm{MPa}$ according to their respective cure times, as determined by oscillating disk rheometer (ODR GT707052). ODR gives digitals outputs of curing characteristics such as scorch time, cure times and torque value.

\subsection{Testing}

Morphological tests: Morphological study was carried out using a Philips, XL30CP scanning electron microscope with a $20 \mathrm{kV}$ accelerating voltage. Phase contrast was improved with a complementary surface preparation techniques via $\mathrm{OsO}_{4}$ staining. Each sample was coated with a thin layer of gold prior to observation under SEM.

Mechanical tests: Tensile and tear specimens were punched out from the molded slab using an ASTM standard die. The mechanical tests were carried out per ASTM D412 and ASTM D1004 for tensile test and tear test, respectively. An Instron 2532 tensile tester and a LLOYD tear resistance tester were both used at a crosshead speed of $500 \mathrm{~mm} / \mathrm{min}$, with a $500 \mathrm{~N}$ load cell.

Automotive fuel resistance tests: the automotive fuel resistance tests were carried out per ASTM D471. Square test specimens of $2 \times 2 \times 2 \mathrm{~cm}^{3}$ were weighed accurately before immersion into the fuel at $25^{\circ} \mathrm{C}$. After a specific time of immersion, a specimen was removed from the fuel and weighed again after removing surface fluids by blotting with filter paper. The percentage of swelling was calculated according to the following equation:

$$
\% \text { swelling }=\frac{\mathrm{W}_{2}-\mathrm{W}_{1}}{\mathrm{~W}_{1}} \times 100
$$


where $\mathrm{W}_{1}$ and $\mathrm{W}_{2}$ represent the weight of the specimens after and prior to immersion into automotive fuel.

\section{Results and Discussion}

\subsection{Cure Characteristic}

The effect of third component content of the NR/FKM blend on the cure characteristics was investigated by ODR. The cure characteristics of the NR/FKM blends; scorch time, cure time and different torque values of NR/ FKM rubber blends between before and after curing (MH-ML) are shown in Figures 2 and 3.

Scorch time is the time taken for the minimum torque value to increase by two units. It is a measure of premature vulcanization of the material. The scorch times of the blends were found to increase by adding ENR but not significantly change with increasing ENR content. As for scorch time, the cure time value also increase by adding ENR and also not significantly change with increasing ENR content. The longer cure characteristic time of the NR/FKM blend with ENR was due to the presence of ENR mean increase the NR phase which susceptible to bonding with peroxide slower than FKM molecule [2].

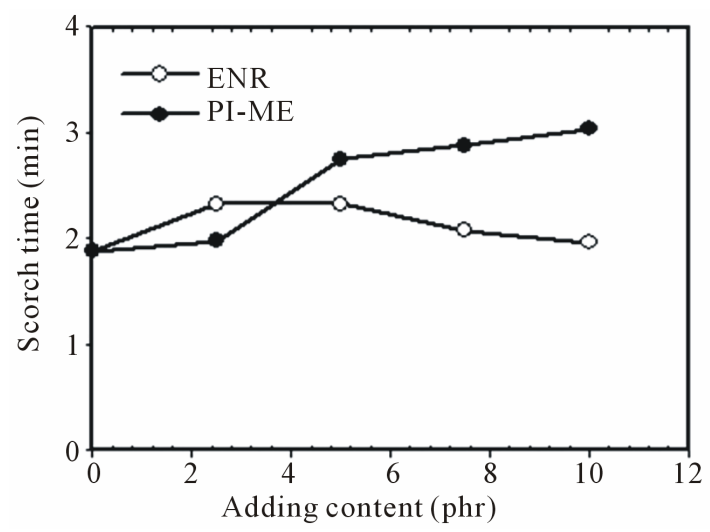

(a)

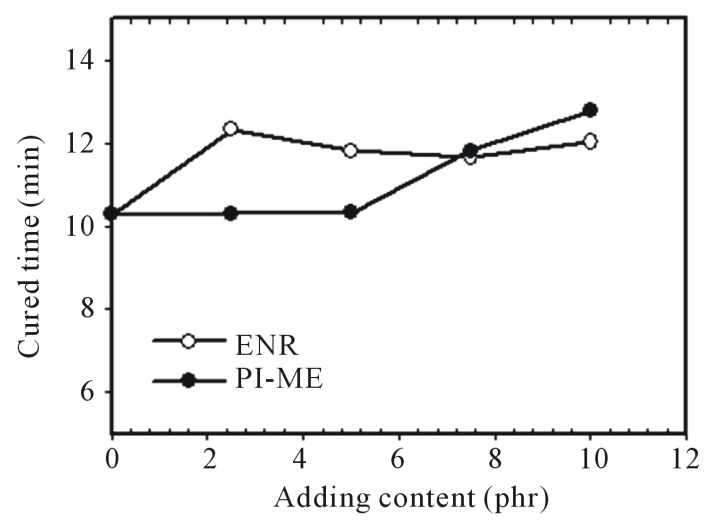

(b)

Figure 2. Cure characteristic time of 70/30 NR/FKM blends with and without third component at $180^{\circ} \mathrm{C}$ (a) scorch time and (b) cured time.

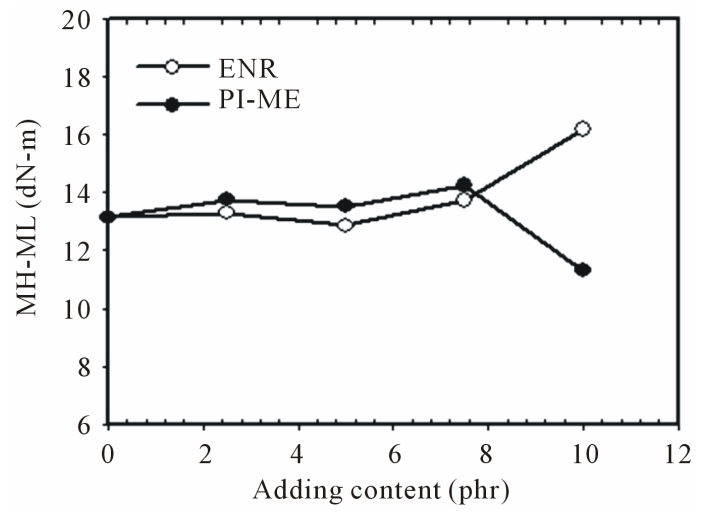

Figure 3. MH-ML of 70/30 NR/FKM blends with and without third component at $180^{\circ} \mathrm{C}$.

However, increasing ENR content was not effect to the cure characteristic time due to insufficient of ENR content in the blend that can enhance peroxide cure reaction.

While adding PI-ME to the blend, the scorch times of the blends were found to increase by increasing PI-ME content. As for scorch time, the cure time value also increased by increasing PI-ME content in the blend. Peroxide curative agent possessed lower efficiency in the presence of acid because the peroxide molecule can react with the acid functional group of PI-ME [9]. Then lowering content of peroxide, rubber blend with PI-PE, slow the cure rate compared to rubber blend without PI-ME.

From Figure 3, ENR content at 2.5 to $5 \mathrm{phr}$ in NR/ FKM blend had no effect on the different torque values (MH-ML), but it was gradually increased by increasing ENR content from 5 to $10 \mathrm{phr}$. NR/FKM blending without ENR has low MH-ML value due to less interaction between NR and FKM molecules [2], however, addition 2.5 to 5 phr of ENR do not increase the MH-ML value due to insufficient of ENR content in the blend that can enhance binding between two phases. The higher ENR content between 5 to $10 \mathrm{phr}$, the higher torque of ODR was achieved. The increasing of ODR torque is the effect on increasing of interaction between two phases of rubber blend. In addition, the higher MH-ML value is represented crosslink density in rubber phases. Addition 10 phr of ENR into NR/FKM blend gives the highest crosslink in the rubber blend.

While adding PI-ME to the blend, PI-ME content at 2.5 to $7.5 \mathrm{phr}$ in NR/FKM blend had no effect on the torque difference (MH-ML), but it was gradually decreased by increasing PI-ME content from 7.5 to 10 phr. The decreasing of ODR torque is the effect on decreasing of the number of crosslink created from the lower molecule of peroxide in the presence of PI-ME. Then adding of PI-ME in NR/FKM has least effect on peroxide cures. In addition, PI-ME was lower molecular weight (ca. 2500) and presented in the liquid form. Higher content of PI-ME, particularly $10 \mathrm{phr}$, PI-ME would act as a lubri- 
cant in the system instead of penetrate into the rubber phase for link between NR and FKM molecules. Thus lower ODR torque was achieved.

\subsection{Morphological Properties}

The SEM micrographs of the cryofracture surfaces of the 70/30 NR/FKM blend without third component were showed in Figure 4. The holes were present in the matrix because phase separation occurred during the fracture. This phenomenon indicates that the interfacial adhesion between NR and FKM is not sufficient and could say this blend was incompatible. To improve blend compatibility, the third component with segments, that was chemically identical or similar to NR and FKM phases, was added. In this study, ENR or PI-ME was used as a third component. It should promote good compatibility between NR and FKM phases in blends.

The influent of ENR content on cryofracture surfaces of the 70/30 NR/FKM blend was showed in Figure 5. A roughness surfaces of the blend can be observed even thought adding ENR. This suggests that adding ENR did not have a remarkable effect on the morphology of NR/ FKM blend.

Figure 6 showed the SEM micrographs of the cryofracture surfaces of the 70/30 NR/FKM blend with 2.5 to $10 \mathrm{phr}$ PI-ME content. Unexpectedly, the addition of PI-ME appeared to increase roughness of the blend. However, PI-ME content did not have a remarkable effect on the surface of the blend. In addition, holes were still presented in the matrix even through added ENR or PI-ME, but more appeared in PI-ME added blend than did in ENR added blend.

\subsection{Mechanical Properties}

The mechanical properties, in terms of tensile strength, elongation at break and tear strength were determined for NR/FKM rubber blends with and without third component, ENR or PI-ME, and the results are reported in Figure 7.

For the ENR added NR/FKM blends, the tensile strength, elongation at break and tear strength were found to not increase significantly with the addition of up to 7.5

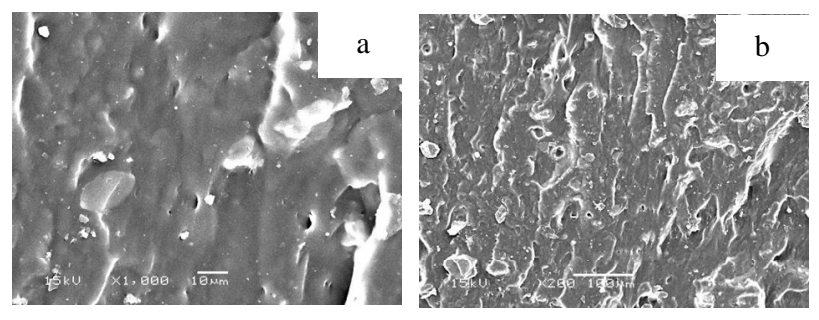

Figure 4. Scanning electron micrograph of cryofracture surface of 70/30 NR/FKM blends without the third component (a) magnificent $\times 200$ and (b) magnificent $\times 1000$.
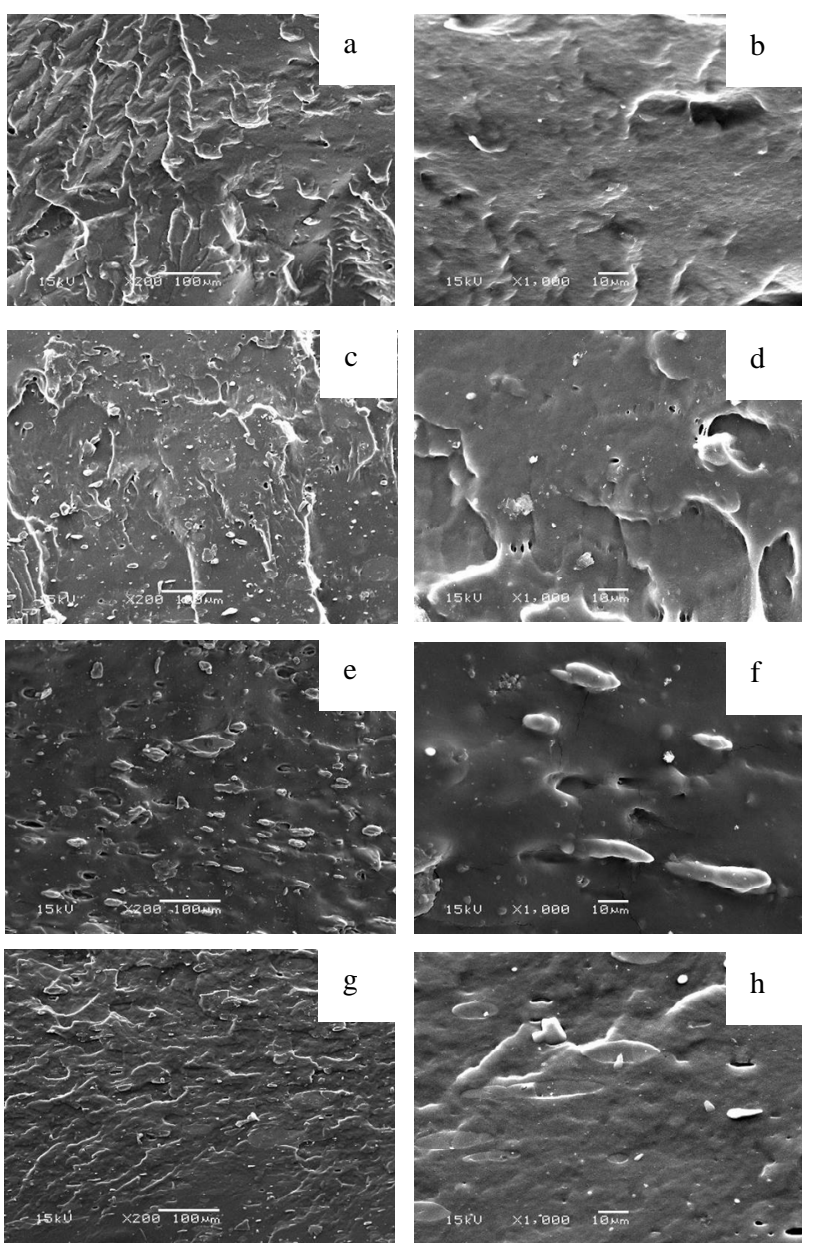

Figure 5. Scanning electron micrograph of cryofracture surface of 70/30 NR/FKM blends with different ENR content ((a), (b)) 2.5 phr ((c), (d)) 5.0 phr ((e), (f)) 7.5 phr and ((g), (h)) 10 phr; ((a), (c), (e), (g)) magnificent $\times 200$ and ((b), (d), (f), (h)) magnificent $\times 1000$.

phr ENR, but subsequently increase progressively at 10 phr ENR at the expense of the tear strength, which was found to decrease with increasing ENR content. It is evident that the mechanical properties of the blend exhibited some extent of improvement with the addition of up to $10 \mathrm{phr}$ ENR. This is due to the achievement of interaction between NR and FKM by ENR molecule at enough ENR content.

For PI-ME added NR/FKM blends, the tensile strength, and tear strength were found to decrease progressively with the addition of up to $10 \mathrm{phr}$ PI-ME. However, the elongation at break was found to not remarkable different with or without PI-ME. It is evident that the mechanical properties of the blend were deteriorated by the addition of up to $10 \mathrm{phr}$ PI-ME. This was due to PI-ME would act as a plasticizer in the system instead of link between NR and FKM molecules. Physically, PI-ME added NR/FKM blends had trend to soft and sticky with increasing PI-ME content. 

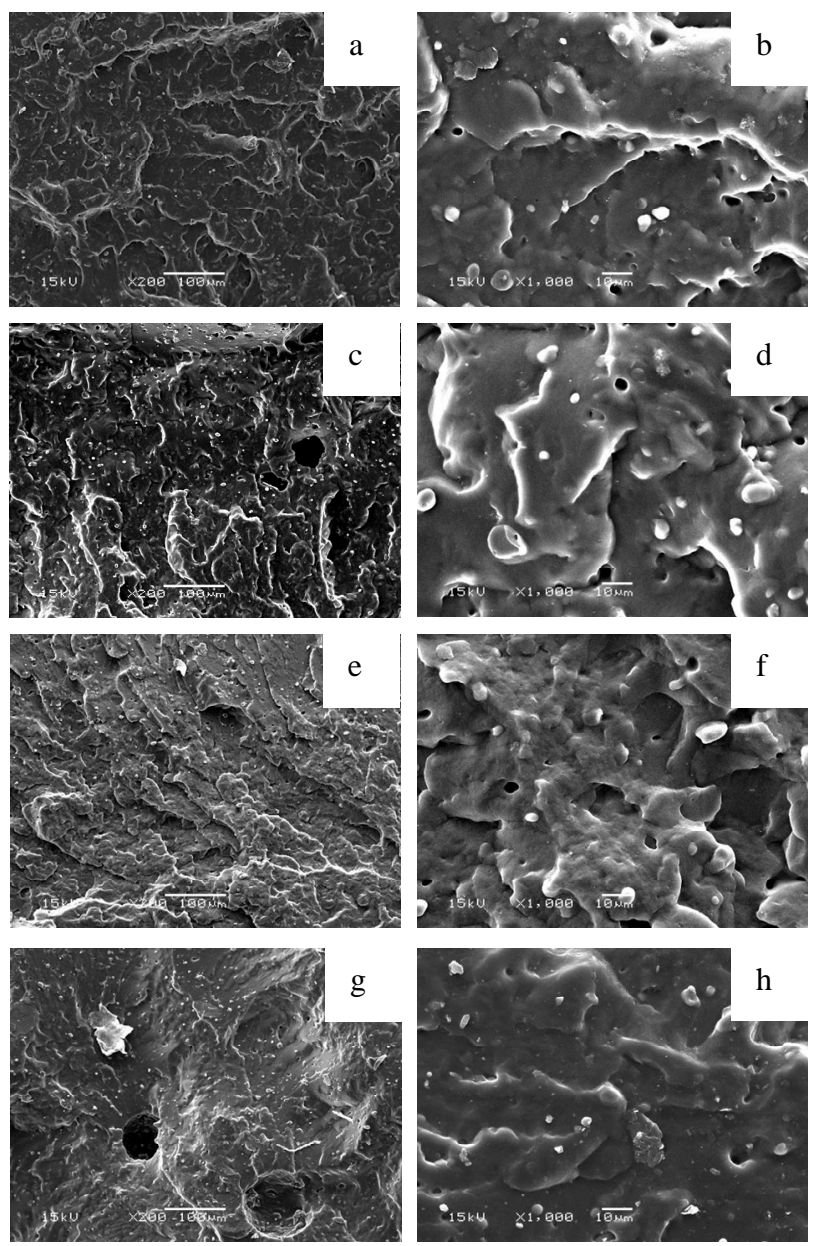

Figure 6. Scanning electron micrograph of cryofracture surface of 70/30 NR/FKM blends with different PI-ME content ((a), (b)) 2.5 phr ((c), (d)) 5.0 phr ((e), (f)) 7.5 phr and ((g), (h)) 10 phr; ((a), (c), (e), (g)) magnificent $\times 200$ and ((b), (d), (f), (h)) magnificent $\times 1000$.

Furthermore, the strength of the blend was depended on degree of crosslinking which confirmed by ODR results. The high strength of the ENR-added blend was due to high degree of crosslinking, while the low strength of the PI-ME-added blend was due to low degree of crosslinking. The results are clearly in good agreement with the cure characteristic results.

\subsection{Automotive Fuel Resistance}

The effect of third component content on automotive fuel resistance of NR/FKM blend was investigated by determined the percentages of swelling as shown in Figure 8. For a given blend composition, the percentages of swelling increased with increasing immersion time. The rate of swelling increased exponentially with time.

For the ENR added NR/FKM blends, it is interesting to note that the percentage of swelling of NR/FKM blend without ENR was greater than that of NR/FKM blend

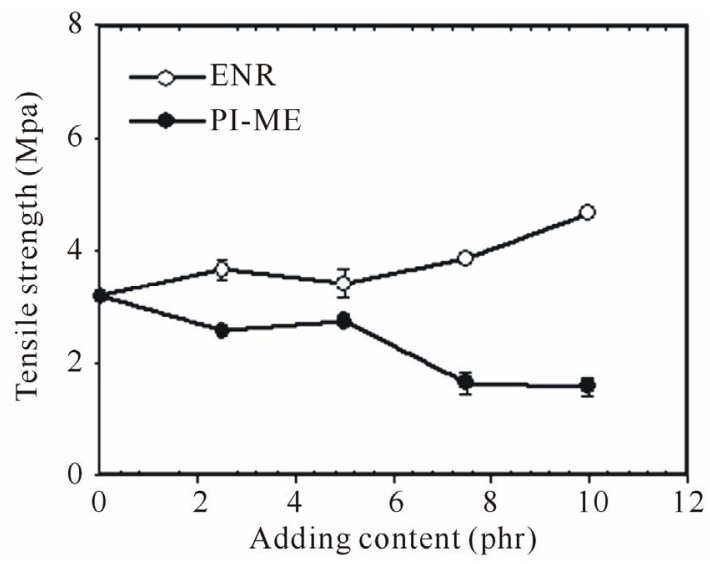

(a)

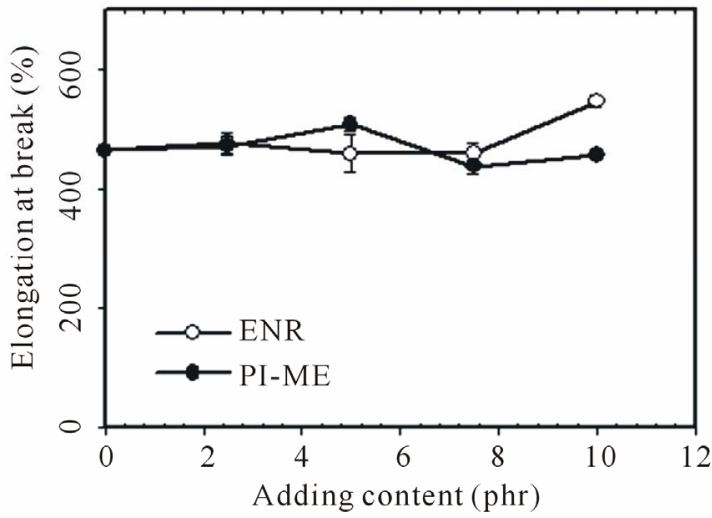

(b)

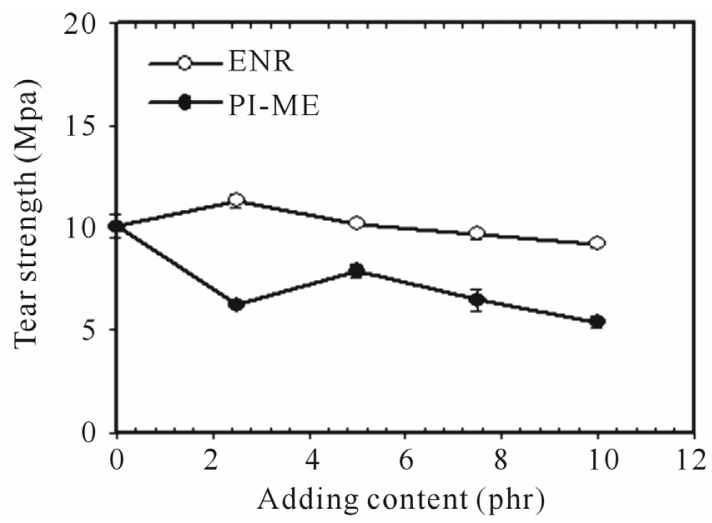

(c)

Figure 7. Mechanical properties of NR/FKM blends with and without the third component (a) tensile strength (b) elongation at break and (c) tear strength.

with ENR for all automotive fuel studies. With increasing ENR content, the percentage of swelling after 100 hours of immersion time of NR/FKM blends was found to decrease when ENR content increased from 2.5 to 10 phr. The NR/FKM blend with high ENR content showed lower degree of swelling than those of the lower ENR content. Because of the improvement of interaction between NR and FKM by ENR molecule at enough ENR 


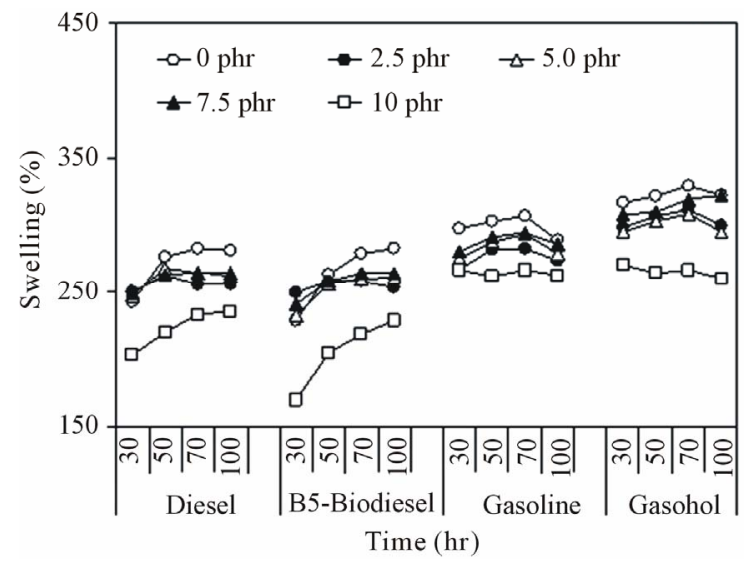

(a)

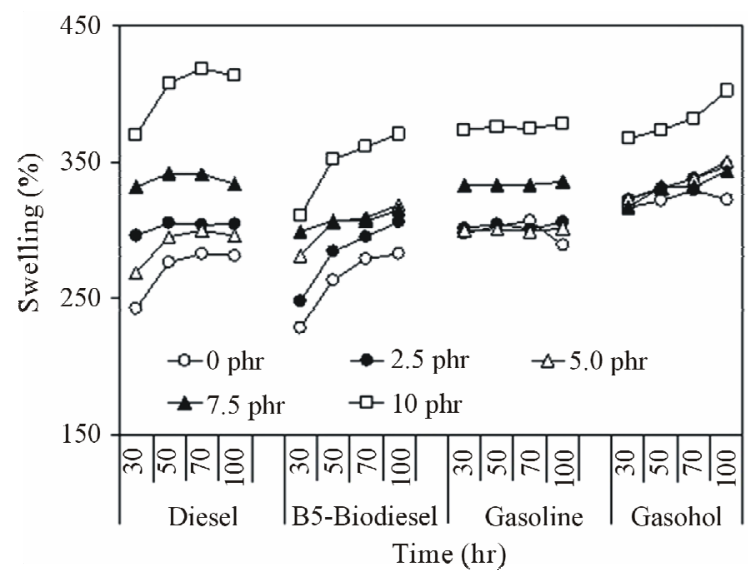

(b)

Figure 8. Percentage of swelling in selected automotive fuels of NR/FKM blends with and without the third component (a) ENR and (b) PI-ME for various immersion time at $25^{\circ} \mathrm{C}$.

content, a result in compatiblized phase in microstructure was occurred. However, the presence of ENR which polar rubber was also increased the oil resistance of the blend.

For the PI-ME added NR/FKM blends, the reverse results were observed. The percentage of swelling of NR/ FKM blend without PI-ME was lower than that of NR/ FKM blend with PI-ME. With increasing PI-ME content, the percentage of swelling of NR/FKM blends was found to increase especially at $10 \mathrm{phr}$. Physically, PI-ME added NR/FKM blends had trend to soft and sticky with increasing PI-ME content. PI-ME would be plasticizer or lubricant in this NR/FKM blend and then allowed automotive fuels penetrate in to the rubber phase. Furthermore, the lower degree of crosslinking in rubber blend in the presence of PI-ME and soft characteristic, a result in higher degree of automotive fuel penetration into rubber phase was occurred. The another reason of high automotive fuel swelling of PI-ME added NR/FKM blend is non-automotive fuel resistance of PI-ME, then increasing PI-ME content result in high percentage of swelling of
NR/FKM blend in automotive fuel.

It was found that the percentage of swelling of NR/ FKM blend with ENR in gasoline-based fuel was quite greater than that in diesel-based fuel (Figure 8(a)). Gasoline is predominantly a mixture of paraffins, naphthanes, and olefins, while diesel is composed of about $75 \%$ saturated hydrocarbons, and $25 \%$ aromatic hydrocarbons [10]. The gasoline-based fuels have a smaller average molecular size than that of diesel-based fuel. Thus gasoline-based fuels were penetrated in ENR added rubber sample easily than diesel-based fuels. This result was as same as previous report [11]. However, for comparing in percentage of swelling of these rubber blends in gasoline-based fuel, gasoline and gasohol, it was found no more different. For NR/FKM blends with PI-ME, the percentage of swelling in all automotive fuel studies was not considerable different (Figure 8(b)).

\section{Conclusion}

In this contribution, NR/FKM blended with blend ratio of 70/30 with and without the third component, ENR or PI-ME was prepared. The curing characteristics, morphology, mechanical properties, and automotive fuel resistance of the rubber blends were investigated. Form the curing characteristics investigation, the cure time and scorch time of the blends with the third component were found to be longer than those of the blends without the third component. Adding ENR did not have a remarkable effect on the morphology of NR/FKM blend but the addition of PI-ME appeared to increase roughness of the blend. The mechanical properties and automotive fuel resistance of the blend rubbers were found to increase with adding 10 phr of ENR due to sufficient ENR content for enhanced interaction between NR and FKM. In contrary results, adding PI-ME into the NR/FKM decreased the mechanical properties and automotive fuel resistance of the blend rubbers especially at $10 \mathrm{phr}$. From the results, it has been concluded that ENR could function as a third component that link NR and FKM phases in the blend system study. The optimum content of ENR was $10 \mathrm{phr}$.

\section{Acknowledgements}

The authors would like to thank for the "Small Projects on Rubber, SPR 50" under supervision of the Thailand Research Fund (TRF) as well as Department of Tool and Materials Engineering, King Mongkut's University of Technology Thonburi for financial support.

\section{REFERENCES}

[1] S. H. EL-Sabbagh, "Compatibility Study of Natural Rubber and Ethylene-propylene-diene Rubber Blends," Journal of Applied Polymer Science, Vol. 90, No. 1, 2003, pp. $1-11$. 
[2] M. Phiriyawirut, "Preparation of Biodiesel Oil Resistance Rubbers from Natural Rubber/Fluoro Elastomer Blends," Proceeding of the 2nd South East Asian Technical University Consortium (SEATUC) Symposium, Bandung, 2008, pp. 50-55.

[3] K. G. Karnika de Silva and M. V. Lewan, "Improving the Morphology and Properties of NR/NBR Blends with NR/ PMMA Graft Copolymers,” In: J. Tinker and K. P. Jones, Eds., Blends of Natural Rubber, A. Chapman \& Hall, London, 1998, pp. 68-78. http://dx.doi.org/10.1007/978-94-011-4922-8_6

[4] K. Prakashan, A. K. Gupta and S. N. Maiti, "Effect of Compatibilizer on Micromechanical Deformations and Morphology of Dispersion in PP/PDMS Blend,” Journal of Applied Polymer Science, Vol. 105, No. 5, 2007, pp. 2858-2867. http://dx.doi.org/10.1002/app.26510

[5] M. N. Radhakrishnan Nair and M. G. Gopinathan Nair, "Compatibility Studied and Characterisation of a PVC/ NR Blend System Using NR/PU Block Copolymer,” Polymer Bulletin, Vol. 56, No. 6, 2006, pp. 619-631. http://dx.doi.org/10.1007/s00289-006-0524-4

[6] G. Guerrica-Echevarría, J. I. Eguiazábal and J. Nazábal, "Influence of Compatibilization on the Mechanical Behavior of Poly(trimethylene terephthalate)/poly(ethyleneoctene) Blends,” European Polymer Journal, Vol. 43, No.
3, 2007, pp. 1027-1037. http://dx.doi.org/10.1016/j.eurpolymj.2006.11.036

[7] K. A. Moly, S. S. Bhagawan, G. Groeninckx and S. Thomas, "Correlation between the Morphology and Dynamic Mechanical Properties of Ethylene Vinyl Acetate/Linear Low-Density Polyethylene Blends: Effects of the Blend Ratio and Compatibilization," Journal of Applied Polymer Science, Vol. 100, No. 6, 2006, pp. 4526-4538. http://dx.doi.org/10.1002/app.22466

[8] M. Abdul Kader and A. K. Bhowmick, "New Miscible Elastomer Blends from Acrylate Rubber and Fluorocarbon Rubber,” Rubber Chemistry and Technology, Vol. 73, No. 5, 2000, pp. 889-901. http://dx.doi.org/10.5254/1.3547627

[9] F. W. Barlow, "Rubber Compounding: Principles, Materials, and Techniques,” Marcel Dekker, Inc., New York, 1988.

[10] Agency for Toxic Substances and Disease Registry (ATSDR), “Toxicological Profile for Fuel Oils,” U.S. Department of Health and Human Services, Public Health Service, 1995.

[11] M. Phiriyawirut and S. Luamlam, "Influence of Poly(vinyl chloride) on Natural Rubber/Chlorosulfonated Polyethylene Blends," Open Journal of Organic Polymer Materials, Vol. 3, 2013. 